\title{
A BIM-Based Smart System for Fire Evacuation
}

\author{
Rania Wehbe * and Isam Shahrour (D) \\ Laboratoire de Génie Civil et Géo-Environnement, University Lille, IMT Lille Douai, JUNIA, ULR 4515-LGCgE, \\ F-59000 Lille, France; isam.shahrour@univ-lille.fr \\ * Correspondence: rania.wehbi@univ-lille.fr
}

check for updates

Citation: Wehbe, R.; Shahrour, I. A BIM-Based Smart System for Fire Evacuation. Future Internet 2021, 13, 221. https://doi.org/10.3390/ fi13090221

Academic Editors: Dino Giuli and Carlos Filipe Da Silva Portela

Received: 12 July 2021

Accepted: 19 August 2021

Published: 25 August 2021

Publisher's Note: MDPI stays neutral with regard to jurisdictional claims in published maps and institutional affiliations.

Copyright: (c) 2021 by the authors. Licensee MDPI, Basel, Switzerland. This article is an open access article distributed under the terms and conditions of the Creative Commons Attribution (CC BY) license (https:// creativecommons.org/licenses/by/ $4.0 /)$.

\begin{abstract}
Building fires constitute a significant threat that affects property, the environment, and human health. The management of this risk requires an efficient fire evacuation system for buildings' occupants. Therefore, a smart fire evacuation system that combines building information modeling (BIM) and smart technologies is proposed. The system provides the following capacities: (i) early fire detection; (ii) the evaluation of environmental data; (iii) the identification of the best evacuation path; and (iv) information for occupants about the best evacuation routes. The system was implemented in a research building at Lille University in France. The results show the system's capacities and benefits, particularly for the identification of the best evacuation paths.
\end{abstract}

Keywords: fire; BIM; Fire Dynamic Simulation (FDS); evacuation; building safety

\section{Introduction}

A comprehensive fire evacuation system is proposed in this study. According to Brushlinsky et al. (2017) [1], fires in buildings cause 44,300 deaths per year. In addition to standards and regulations on fire safety in buildings, significant work has been conducted to improve building occupants' safety during fire evacuation events. The U.S. Fire Administration (2017) [2] reported that in the United States, between 2013 and 2015, around $20 \%$ and $17 \%$ of the fire fatalities in residential buildings were caused by egress problems and escape difficulties, respectively. Scholars have attributed fire evacuation fatalities to poor escape routes, obstacles, and exceeding the required time to escape [3-5]. Research on improving occupants' safety during fire evacuations has focused on: (i) the use of BIM in fire evacuation management; (ii) the development of early fire detection systems; and (iii) the use of Fire Dynamic Simulation (FDS) and Agent-Based Simulation (ABS) to optimize evacuation routes.

Since a building's geometry and space distribution play a significant role in the propagation of fires and the evacuation of occupants, they should be adequately considered in the building's fire evacuation management [6]. BIM is a powerful tool for risk management [7-12], especially disaster and emergency response management [13,14]. BIM has been used together with several technologies to improve safety indoors by: (i) locating and tracking occupants inside a building [15,16]; (ii) generating evacuation paths in real time [17-19]; and (iii) guiding users through BIM and mobile applications [14,20]. Shiau et al. (2013) [21] proposed a BIM web-based fire management system that detects fire events and collects information about the building's occupants. It enables firefighters to access online information about the fire conditions and fire-fighting equipment. Wang et al. (2014) [22] developed a BIM-based virtual environment to improve the management of emergencies in buildings. They focused on real-time two-way information flow and occupants' evacuation. Cheng et al. (2017) [20] proposed an intelligent system for indoor fire prediction and disaster relief that uses BIM and Bluetooth sensors to collect data on the environment and determine the best evacuation routes. In addition, a mobile application was developed to help evacuees and firefighters during fire tragedies.

Research on early fire detection focuses on using the Internet of Things (IoT) and Artificial Intelligence (AI) to improve the evacuation of a building's occupants during 
a fire emergency and the building's safety. For example, the IoT was used to monitor the temperature and smoke and carbon dioxide levels indoors [23-25] and the indoor location of a building's occupants [26]. The IoT was also used to shut down critical equipment, such as the power supply, and turn on sprinklers $[27,28]$. In addition, some scholars used AI to identify the source of the fire [29] and rapid evacuation routes [30].

The FDS tool has been used to visualize the fire's growth and simulate the spread of substances in a given time interval. Jevtic (2016) [31] highlighted the FDS tool's potential to: (1) plan the location of fire detectors; (2) illustrate the fire's spread; (3) predict the fire; and (4) determine the evacuation routes. Long et al. (2017) and Xu and Peng (2020) [32,33] presented a numerical fire and evacuation simulation for buildings. They showed that coupling FDS and ABS provides a reasonable estimation of the evacuation time [34,35]. Zhang et al. (2019) [29] developed a real-time indoor location system by combining BIM, Bluetooth connectivity, and a mobile application. The system automatically evaluates evacuation scenarios using real-time sensor data as well as simulation capacities. Mirahadi et al. (2019) [17] developed a BIM-based simulation framework that combines FDS and ABS. It permits the simulation of a fire's spread and evacuation scenarios for several building layouts.

Previous research did not develop a comprehensive solution for the evacuation of a building's occupants during a fire. To fill this gap, in this article we present and discuss a smart system for fire evacuation management that is inspired by the smart building concept. It uses BIM for the spatial modeling of the building and the fire evacuation system. The basic layers of smart systems, including the monitoring layer, the data processing and analysis layer, the control layer, and the smart services layer, were used. The system uses FDS and ABS to determine the Available Safe Egress Time (ASET).

This remainder of this article is structured as follows. Section 2 presents the methodology and materials used in this study and the architecture of the proposed smart system for fire evacuation management. Section 3 presents the application of the smart fire evacuation system to a research building at Lille University. Section 4 provides our conclusions.

\section{Materials and Methods}

The smart fire evacuation system, which is inspired by the smart building concept, aims to ensure early detection of fires in a building, interact with users, identify the optimal evacuation paths, and share information with the building's occupants and managers and emergency services. BIM is used to: (i) model the building and the fire system; (ii) visualize events and parameters related to the evacuation of the building's occupants during a fire in real time; and (iii) identify the optimal evacuation paths. The latter is based on software for fire evacuation paths and Machine Learning (ML). In addition, the IoT and mobile applications are used to collect data and control critical equipment. The following sections present the architecture of this system and its main layers.

\subsection{Smart Evacuation System Framework}

The smart evacuation system is composed of five layers (Figure 1): (1) a physical layer; (2) a monitoring layer; (3) a smart platform layer; (4) a control and alert layer; and (5) a smart services layer. The following sections present each of the layers of this system.

\section{Physical Layer}

Fire propagation and people evacuation are affected by the building's geometry and space distribution [6]. Consequently, the fire evacuation system should include data concerning the spatial organization of the building, materials used in the construction, building equipment, and the fire components. The building's geometry information is required for indoor navigation by considering the obstacles (walls, columns, furniture) and doors. The building materials' characteristics, including their thermal properties, are necessary for simulating fire scenarios, understanding spaces' function, and equipment location to help recognize the fire source and severity. Moreover, data related to the firefighting equipment such as fire detectors, extinguishers, alarms, and emergency evacuation should be inte- 
grated into the model for optimal evacuation management. Finally, data concerning the physical layer are integrated into the BIM model and shared with users, the management team, and emergency services.

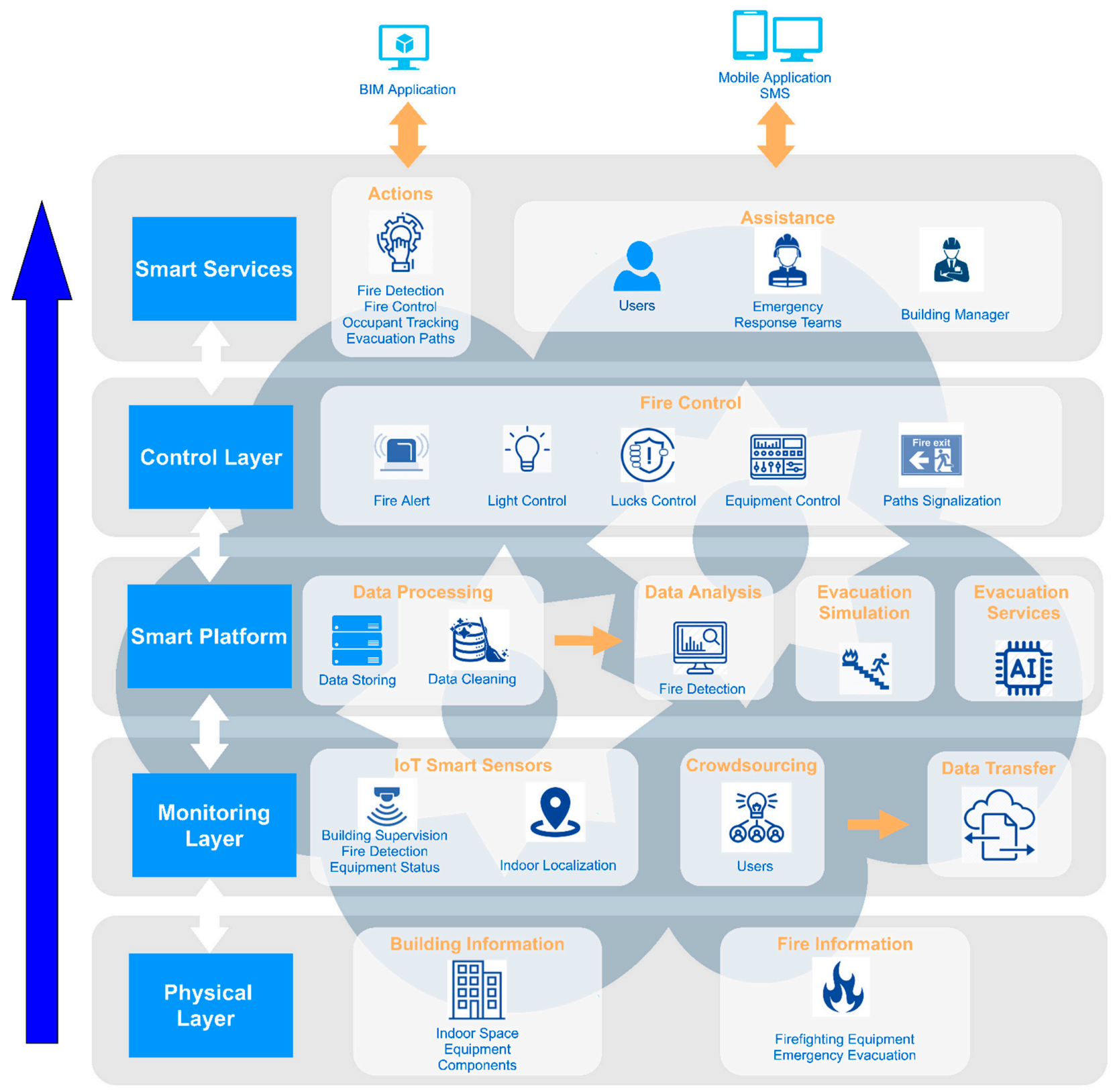

Figure 1. Architecture of the smart evacuation system.

\section{Monitoring Layer}

Smart sensors are used for building supervision and fire evacuation management. Detectors are used to monitor flames, heat, smoke, and other combustion products. The most commonly used sensors to deal with fire hazards are temperature, smoke, and Carbon Dioxide $\left(\mathrm{CO}_{2}\right)$. Sensors collect and transmit data to the system in real time. They are placed in critical locations to collect and share data with the smart platform.

The real-time location of humans in the building constitutes a vital issue in evacuation management. A wide variety of Radio Frequency (RF) sensors are used for real-time location systems (RTLS). However, most of these sensors do not provide accurate results and coverage. Therefore, Ultra-Wide Band (UWB) is used for comprehensive fire risk management $[36,37]$. 
Data transfer is accomplished via wired or wireless technologies. Wireless networks transmit collected data to the server, where data are processed and analyzed. Routers are installed inside the buildings to ensure good communication coverage. Each router operates as a checkpoint to take over the other router task and transfer it to the next one.

Users effectively participate in fire evacuation management by using mobile applications to share real-time information about the fire event.

\section{Smart Platform}

This layer comprises both data processing and analysis.

- Data Processing: Data processing includes data cleaning and storage. Data cleaning aims to detect inaccurate records to replace, modify, or even delete the coarse data. This step is important since incorrect or irrelevant data can lead to a wrong action. For this reason, data collected from sensors and stakeholders should be cleaned to avoid bad decisions. Data storage concerns the integration of collected data in one database. Furthermore, the platform offers the ability to access the storage to search for a particular event. To realize this task, the platform must be accompanied by a XQuery that links the database with the Web world. XQuery allows access to the database by granting the possibility to store, extract, and manipulate data.

- Data Analysis: Data analysis aims to transform the collected data into operational data, which improves fire evacuation operations. The BIM environment offers the capacity to set up norms, including minor and upper limits for sensors; whenever these boundaries are reached, BIM could identify the fire source and type. These norms concern temperature, $\mathrm{CO}_{2}$, and smoke.

- Evacuation Simulation: FDS generates several fire scenarios based on different fire locations, types, and severity. The fire reaction should be created, and smoke devices should be placed at critical points. Over the FDS, the fire extension and the environmental data such as temperature, smoke, and air intoxication are estimated. According to the tenability boundaries, the ASET is computed for proposed scenarios, including visibility, temperature, smoke, and air intoxication [38]. ABS should be conducted for fire scenarios to determine the appropriate evacuation paths. FDS should be integrated with ABS to investigate the impact of fire on occupants' movement and evacuation paths. Steering mode is used to deviate occupants from risky paths that could include obstacles, high smoke density, low visibility, and high Carbon Monoxide (CO) concentration. Accordingly, the model selects the evacuation path depending on (1) FDS parameters; (2) queue time to evacuation exits; (3) estimated time from each door to exit; and (4) the total travel distance to stay safe [39].

- Evacuation services: AI is used to determine the optimal solution by analyzing historical and real-time data. AI proved to be effective in resilient fire hazard management [40]. The system is based on an ML algorithm implemented in Dynamo. When BIM detects a fire source through sensors and identifies its cause and location, the system automatically generates the optimal evacuation solution by analyzing the historical data. The advantage of AI lies in self-learning, reasoning, and adaptation of the best fire evacuation scenario from the previous scenarios generated and incorporated in the database.

\section{Control and Alert Layer}

Based on the IoT smart sensors and data analysis, the system provides fire alerts. Detection and alarm services help to sound an alarm or other signals to alert the fire emergency service. In addition, it conducts actions for fire defenses such as closing doors, turning off equipment, automatic fire suppression, or smoke control systems. In other words, the system takes adequate measures concerning lucks, light, and critical equipment control to limit the fire's spread and related damage. It also provides light and voice path signalization. The proposed system could be directly connected to the existing fire security system, including sensors and alarms. The Dynamo tool can connect existing systems with the proposed one to provide additional services for users. 


\section{Smart Services}

The system offers valuable services via BIM, such as: (1) detecting the fire's location, cause, and type; (2) tracking the occupants and defining their locations; (3) displaying the environmental data; (4) sounding the alert; (5) identifying the optimal evacuation paths; (6) taking decisions to limit the fire's spread such as shutting off equipment.

\subsection{Fire Evacuation System Operation Mechanism}

The building's spatial layout and information are vital for a fire evacuation system. The minimum Level of Development (LOD) provided for the BIM Model is LOD 300, which presents the building components' geometry, material properties, and equipment $[35,41]$. The smart sensors will be integrated into the BIM model. Data will be stored in the database connected to Dynamo, so data could be visualized and analyzed in real time using the BIM model. After data analysis, the system will identify the fire location, category, and severity and prevent false detection. Whenever the system scans and extrapolates the fire's characteristics, evacuation paths will be generated using the fire simulation and evacuation modules' history.

Several fire sources and locations are simulated to create an FDS database. The tenability boundaries, including visibility, temperature, $\mathrm{CO}$ concentration, and smoke density, should be checked to validate the scenarios, as shown in Table 1.

Table 1. Tenability boundaries for ASET calculation.

\begin{tabular}{cc}
\hline Tenability & Tenability Boundaries \\
\hline Smoke Density & $>85 \%$ \\
\hline Visibility & $13 \mathrm{~m}$ \\
\hline Temperature & $60{ }^{\circ} \mathrm{C}$ \\
\hline Air Intoxication: CO & $2500 \mathrm{ppm}$ \\
\hline
\end{tabular}

\section{Visibility}

Visibility is considered a significant cause of human injuries and fatalities during building fires. In the initial fire phase, smoke is released due to blazing. Smoke comprises many toxic gases and small particles, which could smother or poison the stuck personnel. Particles in the smoke decrease humans' visibility, which leads to difficulty in escaping from the building. Smoke will become thicker with time and due to the fire's growth. Therefore, the visibility limit should be considered because the evacuation route could no longer be visible. The critical smoke height (Hc) is calculated based on Equation (1) [33].

$$
\mathrm{Hc}=\mathrm{Hp}+0.1 \mathrm{Hb}
$$

$\mathrm{Hp}$ is the typical height of eyes taken equal to 0.8 of human height, and $\mathrm{Hb}$ corresponds to the floor height.

The FRI Research Institute states that the relation between visibility and smoke density could be computed using Equation (2) [42]:

$$
\mathrm{S}=\frac{\mathrm{K}}{\mathrm{e}}
$$

$\mathrm{S}$ is the visibility in meters, $\mathrm{K}$ is the proportionality constant that depends on the illumination of the evacuation sign, and e is the extinction coefficient $(1 / \mathrm{m})$.

To start being emotionally affected by smoke, a value of $e=0.1(1 / \mathrm{m})$ is enough, and to start showing strong emotional fluctuation, a range of e [0.35-0.55] is considered [38]. However, it should be noted that during fire hazards, occupants are affected psychologically by fear. Therefore, a value of $\mathrm{e}=0.15(1 / \mathrm{m})$ is considered as the maximum allowable density during evacuation. On the other hand, this value considers the tenants unfamiliar with 
the building's architecture, which constitutes the worst-case scenario. For e $=0.15$, the visibility limit $S$ for unfamiliar occupants is $13 \mathrm{~m}$. For a familiar resident, e can be taken as 0.5 , which gives a visibility limit $S=4$ [43]. Humans will have visibility and mobility difficulties when the smoke density exceeds $85 \%$ [44].

\section{Temperature}

High temperatures can cause heatstroke, burns, and respiratory issues. The heat produced will start to impact the human body once (1) its upper layer radiation strength exceeds $180{ }^{\circ} \mathrm{C}$ and (2) the smoke layer of direct contact with the human body exceeds $60^{\circ} \mathrm{C}$ [45].

\section{Gas intoxication}

Gases that affect occupants are $\mathrm{CO}, \mathrm{CO}_{2}$, and hydrogen cyanide $(\mathrm{HcN})$. $\mathrm{CO}$ is considered the primary toxic gas during a fire [46]. The $\mathrm{CO}$ toxicity concentration harms humans when it exceeds 2500 ppm [47].

The FDS data are exported to Pathfinder to simulate the evacuation paths. According to Thornton et al. (2014) [48], Pathfinder is considered a reliable ABS tool to simulate evacuation. Pathfinder takes into consideration the building's complexity, geometry, obstacles, and human parameters. However, it does not simulate fire, smoke density, visibility, and temperature during evacuation. The program allows users to take FDS results and plug these data during simulation, allowing designers to investigate the impact of each parameter on occupants' movement and evacuation path.

Peacock et al. (2011) [49] analyzed different buildings with various stories and geometry to study the occupants' movement while evacuating. An overall speed of $0.78 \mathrm{~m} / \mathrm{s}$ was recommended. Moreover, Pathfinder changes the speed dynamically in response to obstacles, geometry (flat terrain, stairs, ramp), and fire impact, making the simulation more realistic. To achieve the best decision-making, several models should be simulated with different occupant numbers, densities, and characteristics. The fire and evacuation simulations database is integrated into Dynamo to be used with AI for selecting the optimal evacuation paths. ML is based on training data from fire scenarios based on fire location, type, and intensity. According to FDS and ABS, selected by ML, Dynamo's optimal evacuation paths from rooms will be generated.

\section{Application to a Research Building of Lille University}

\subsection{Presentation of the Building}

The smart evacuation system was applied to the 4th floor of the research building ESPRIT of Lille University, which hosts the Civil Engineering and Geo-Environment Laboratory (LGCgE). The total area of this space is equal to $1256 \mathrm{~m}^{2}$. It includes offices, technical rooms, kitchen, and WCs. This space hosts about 50 users, including faculty members, Ph.D. students, and technical staff. Figure 2 shows the BIM model of the ESPRIT building by providing a 3D section in the LGCgE laboratory, including the building's geometry, compartments, and components. The BIM model provides data and information to the fire simulation module to (i) estimate the fire expansion configuration; (ii) identify the suitable egress routes for each partition; and (iii) assist as a basis for the agent simulation module.

Figure 3 illustrates the LGCgE main entrance with the fire equipment, emergency evacuation, and sensors. The fire equipment includes fire detectors, extinguishers, and alarms. In addition, the space is equipped with multi-sensors, including environmental sensors such as temperature, humidity, indoor air quality, and open/close sensors for windows and doors. Through these sensors, the system can monitor and interact in real time during the fire. 


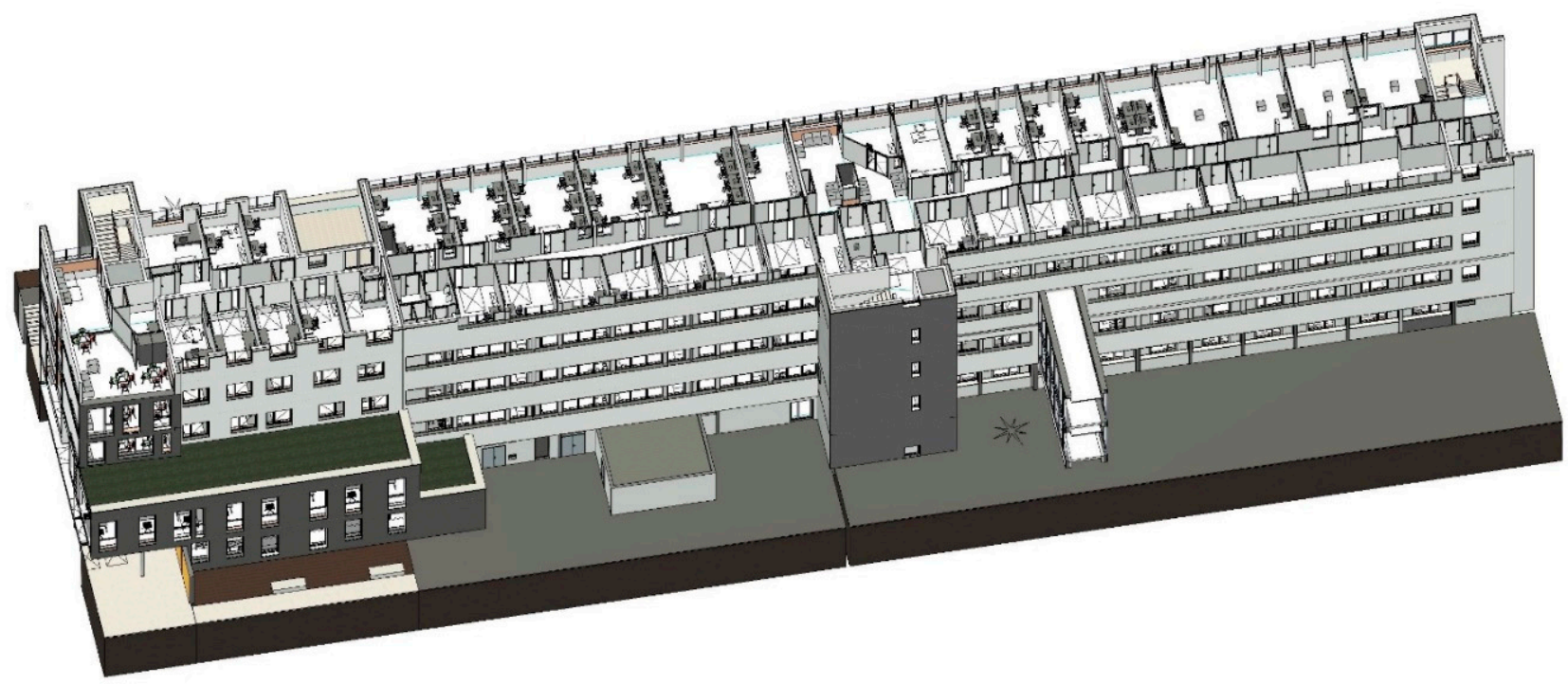

Figure 2. BIM model of the LGCgE space of ESPRIT building (Lille University).

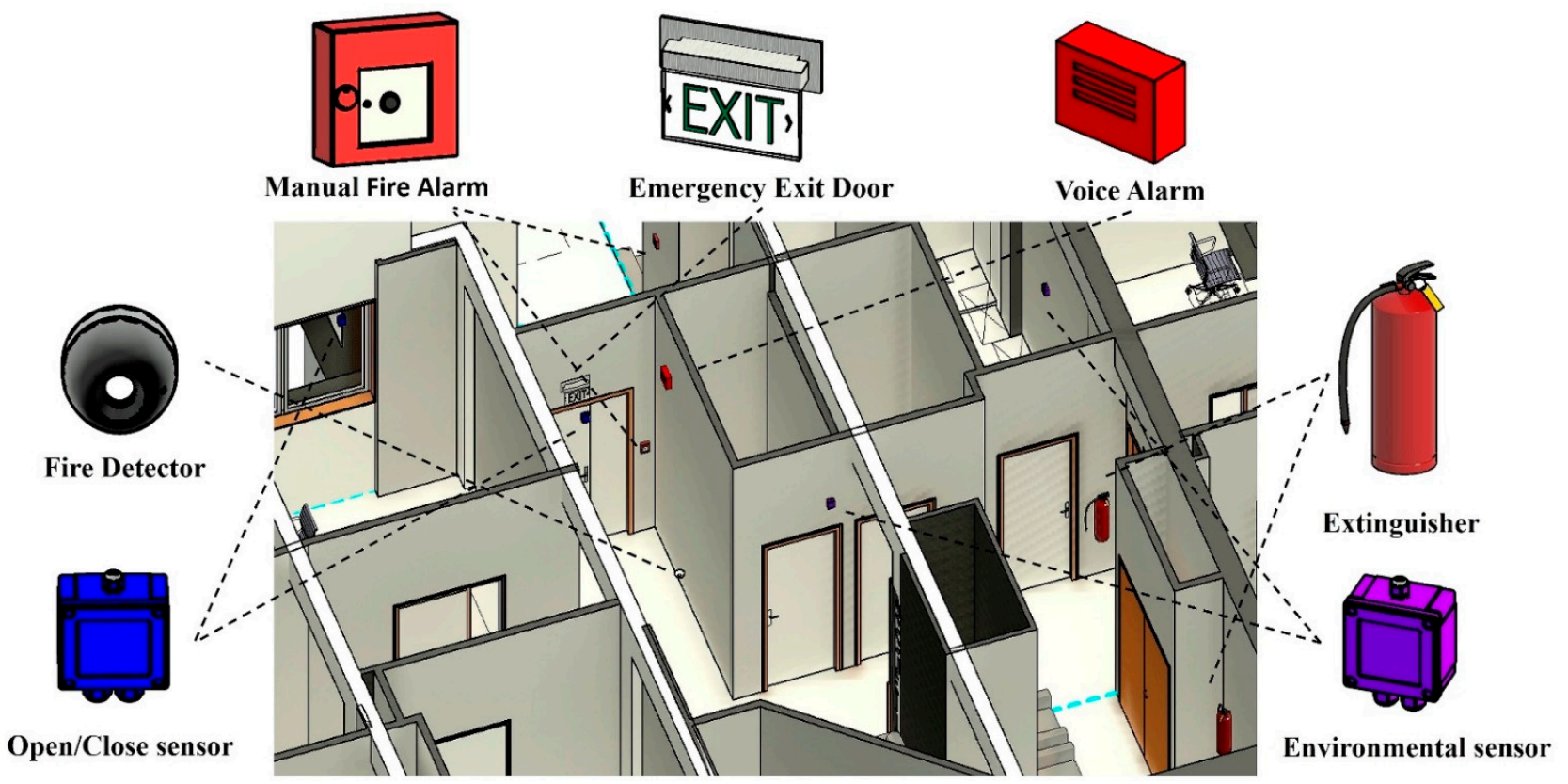

Figure 3. Fire information in the BIM model.

\subsection{Fire Simulation}

Fire scenarios were simulated with two fire sources to highlight critical areas. Figure 4 shows the fire's location and the emergency exit doors. The first scenario corresponds to a fire event in the kitchen due to a gas burner, while the second is related to an electrical fault in an electrical room.

Each fire scenario was modeled with input data from the European guidelines [50]. The simulation time for both scenarios was set to $900 \mathrm{~s}$. Measurement slice plans and critical points should be located in the model to measure the CO concentration, visibility, and temperature at the critical height based on Equation (1). The average human height in this study is considered $1.7 \mathrm{~m}$; accordingly, $\mathrm{Hp}$ is equal to 1.36 . $\mathrm{Hb}$ corresponds to a floor height of $3.3 \mathrm{~m}$. Therefore, the critical height is equal to $1.69 \mathrm{~m}$. 


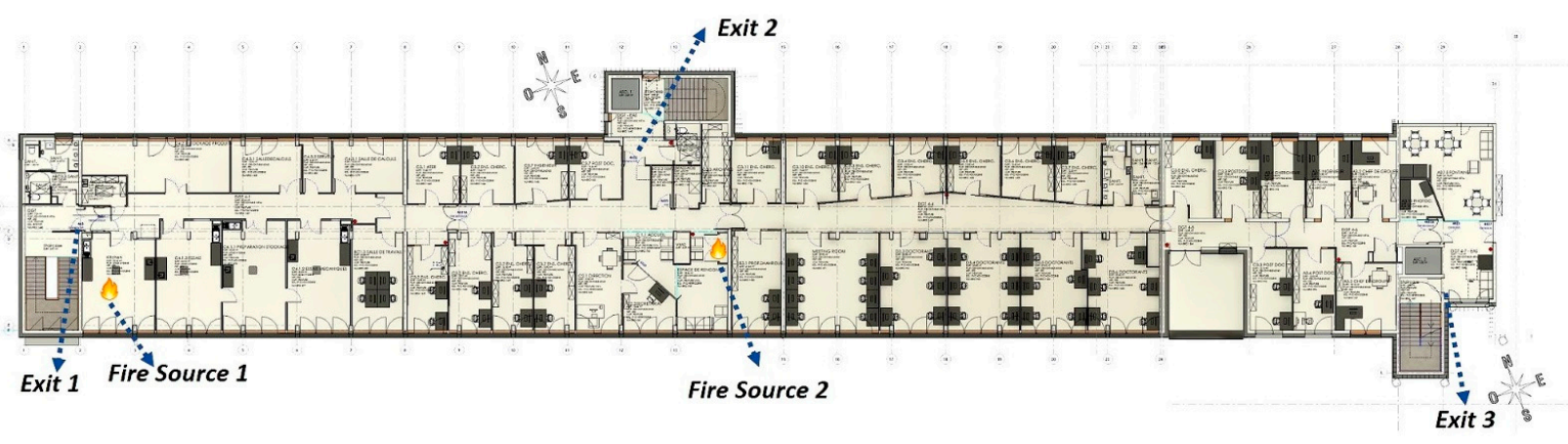

Figure 4. LGCgE plan view—fire simulation input.

The CO concentration was under $2500 \mathrm{ppm}$ for both scenarios; therefore, the $\mathrm{CO}$ data were not used for ASET computation. For the first scenario, the smoke density, visibility, and temperature variation during the fire simulation are illustrated in Figure 5. Exit 1 is the most affected because it is closest to the fire source. The smoke reaches its limit at exit 1 within $27 \mathrm{~s}$ (Figure 5a), the visibility attains $13 \mathrm{~m}$ at $52 \mathrm{~s}$ (Figure $5 \mathrm{c}$ ), and the temperature reaches $60^{\circ} \mathrm{C}$ (Figure $5 \mathrm{~b}$ ) at $91 \mathrm{~s}$. The smoke continues to grow and reaches exit 2 (265 s), then exit 3 (337 s), before starting by impacting the floor below around $340 \mathrm{~s}$. The occupants near exit 2 (203 s) have visibility difficulty before exit 3 (546 s). According to Table 2, exit 1 is impassable after $27 \mathrm{~s}$ (first ASET stage), exit 2 is blocked at $203 \mathrm{~s} \mathrm{(second}$ ASET stage), and exit 3 at $334 \mathrm{~s}$ (third ASET stage).
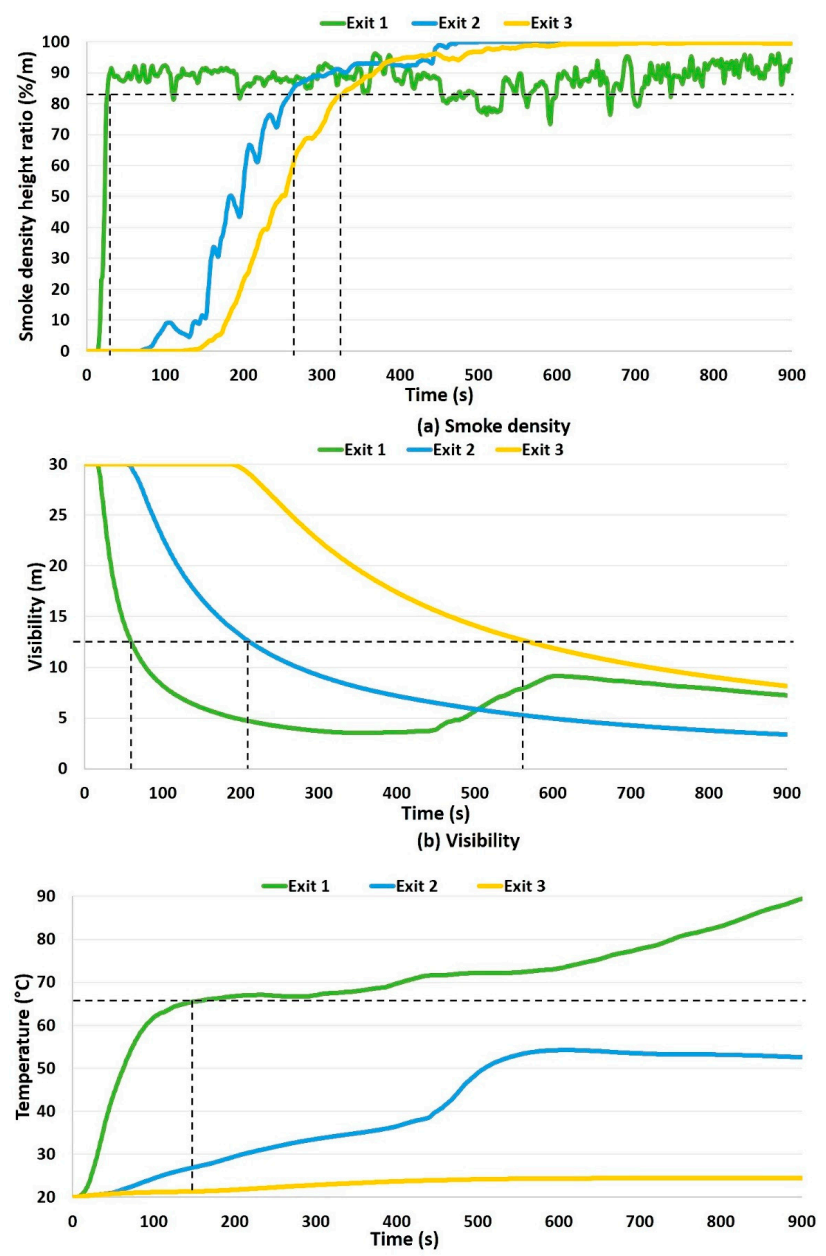

(c) Temperature

Figure 5. Tenability variation for the first scenario (kitchen fire scenario). 
Table 2. ASET computation for door exits in the first scenario (kitchen fire scenario).

\begin{tabular}{cccc}
\hline Limits & Exit 1 & Exit 2 & Exit 3 \\
\hline Smoke Density & $27 \mathrm{~s}$ & $265 \mathrm{~s}$ & $337 \mathrm{~s}$ \\
\hline Visibility & $58 \mathrm{~s}$ & $203 \mathrm{~s}$ & $546 \mathrm{~s}$ \\
\hline Temperature & $91 \mathrm{~s}$ & NA & NA \\
\hline ASET & $27 \mathrm{~s}$ & $203 \mathrm{~s}$ & $337 \mathrm{~s}$ \\
\hline
\end{tabular}

The electrical fault is close to exit 2. Thus, the occupants' visibility is first impacted at this exit (83 s) (Figure 6b). The smoke density boundary reaches exit 3 (254 s) before exit 1 (441 s) (Figure 6a). In this scenario, the maximum temperature $\left(50{ }^{\circ} \mathrm{C}\right)$ occurs at exit 2 (Figure 6c). Based on Table 3, the exits are blocked as follows: exit 2 at 83 s (first ASET stage), exit 3 at $254 \mathrm{~s}$ (second ASET stage), and exit 1 at $441 \mathrm{~s}$ (third ASET stage).

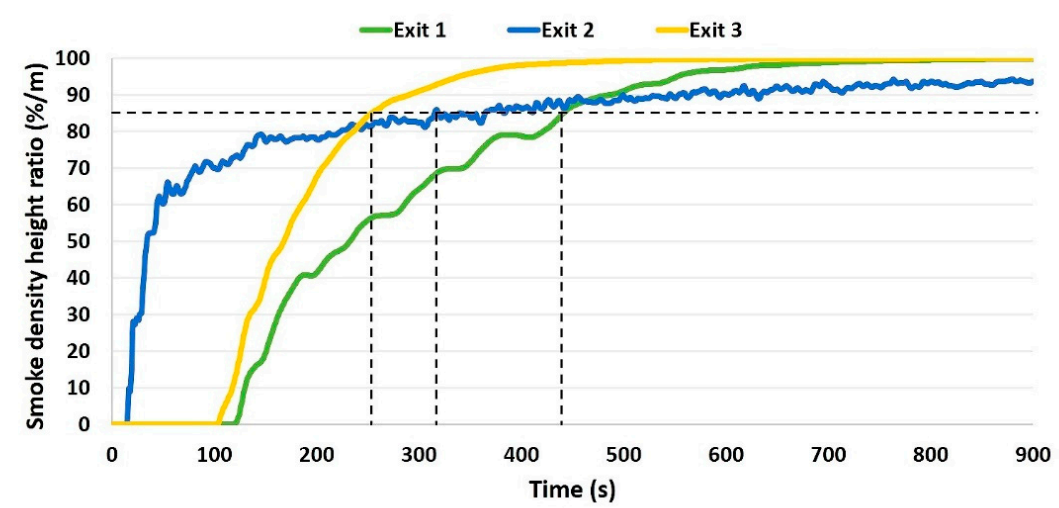

(a) Smoke Density

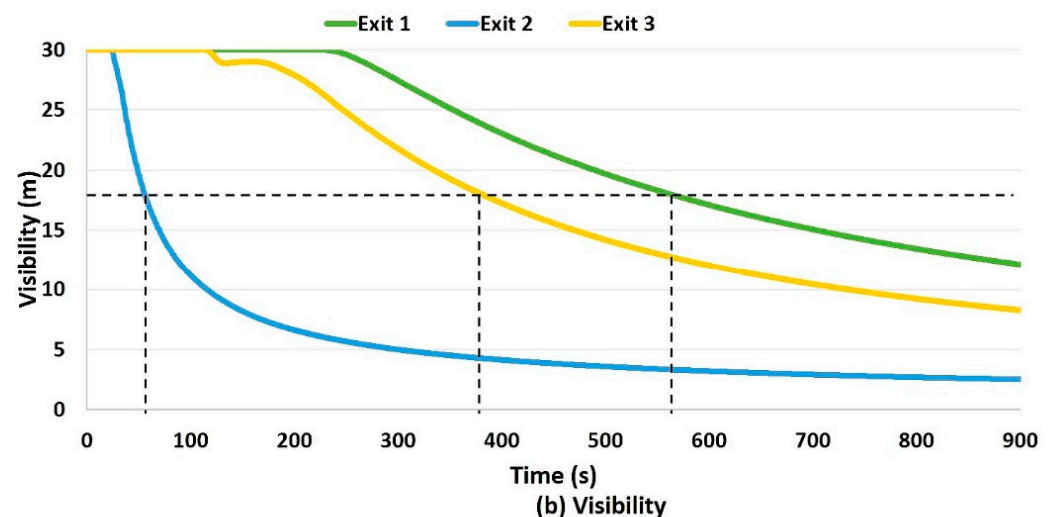

(b) Visibility

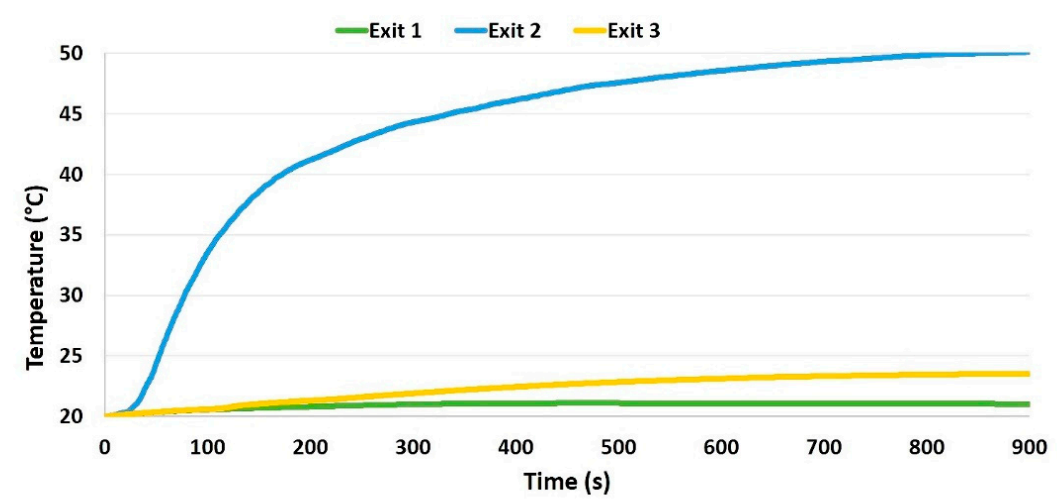

(c) Temperature

Figure 6. The tenability variations with time for the second scenario (electrical fire scenario). 
Table 3. ASET computation for door exits in the second scenario (electrical fire scenario).

\begin{tabular}{cccc}
\hline Limits & Exit 1 & Exit 2 & Exit 3 \\
\hline Smoke Density & $441 \mathrm{~s}$ & $316 \mathrm{~s}$ & $254 \mathrm{~s}$ \\
\hline Visibility & $585 \mathrm{~s}$ & $83 \mathrm{~s}$ & $549 \mathrm{~s}$ \\
\hline Temperature & NA & NA & NA \\
\hline ASET & $441 \mathrm{~s}$ & $83 \mathrm{~s}$ & $254 \mathrm{~s}$ \\
\hline
\end{tabular}

\subsection{Agent-Based Evacuation Simulation (ABS)}

According to Khandoker et al. (2018) [51], the generated heat, smoke density, and toxicity concentration constitute the main features that affect the occupants' movement. Therefore, the FDS simulations are integrated into Pathfinder to consider humans' movement during the fire. Fifty occupants are distributed randomly in the laboratory, where at least one occupant is placed in each room. The Required Safe Egress Time (RSET) and the exit door used by each occupant were computed. The simulation validation was conducted by checking that the RSET is less than the ASET for all occupants. Several evacuation simulations need to be performed to achieve the optimum goal while using Pathfinder to derive the optimum set of instructions for each tenant considering the real-time location.

Figure 7 shows, for the kitchen fire scenario, the difference in flow rates between the evacuation under normal conditions and fire circumstances. It indicates that under normal situations, the flow rates on each exit are smooth compared to fire incidents. However, the latter fluctuates all along the evacuation process. Moreover, the total evacuation time in normal conditions is $54.5 \mathrm{~s}$ compared to $251.5 \mathrm{~s}$ during the fire. This important change in the evacuation time is due to visibility losses and smoke.

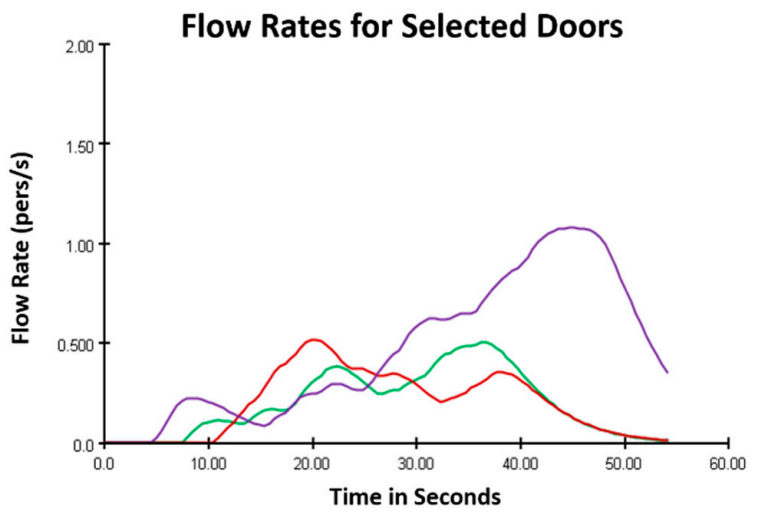

(a) Normal Situation
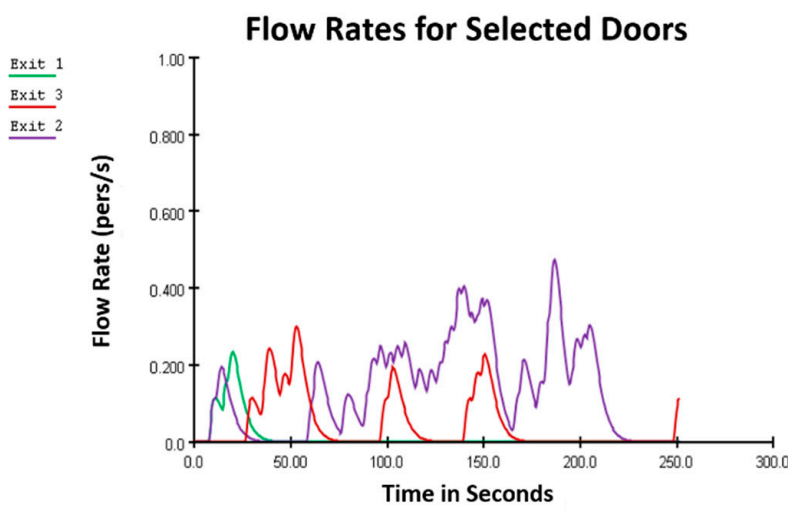

(b) Fire Incident

Figure 7. Impact of fire on the indoor occupants' flow rate (kitchen fire scenario).

Figure 8 shows that only three occupants used exit 1 during the fire event compared to 11 occupants in normal conditions. This means that most occupants near exit 1 changed their direction to exit 2 because the fire location was close to exit 1 . Accordingly, the model guides occupants based on the safest path more than the quickest ones. It should be noted that occupants reached the exit doors in less time than the ASET derived from PyroSim.

For the electrical fire scenario, the total time for evacuation under FDS conditions is equal to $209.5 \mathrm{~s}$. The flow rates illustrated in Figure 9 indicate a significant change in the occupants' behavior. For example, 14 occupants out of 28 changed exit 2 to exit 1 or exit 3 under fire circumstances. Moreover, the model respects the 83 s ASET for exit 2, confirming that the model privileges the safest evacuation paths. 


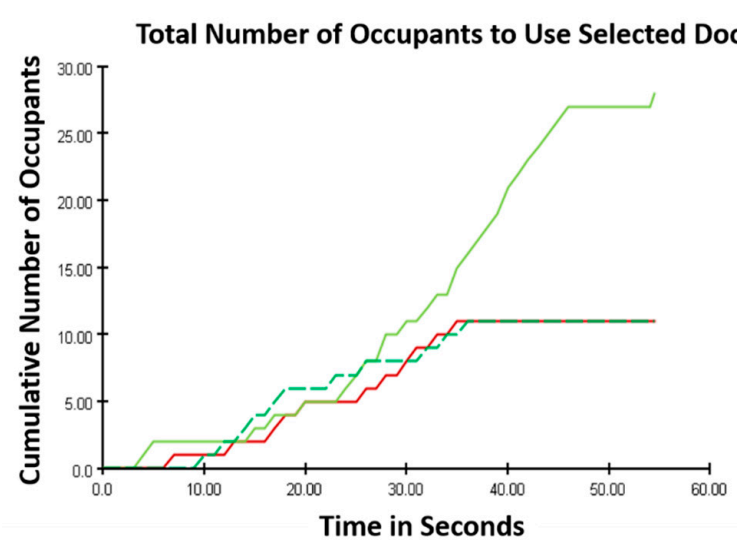

(a) Normal Situation

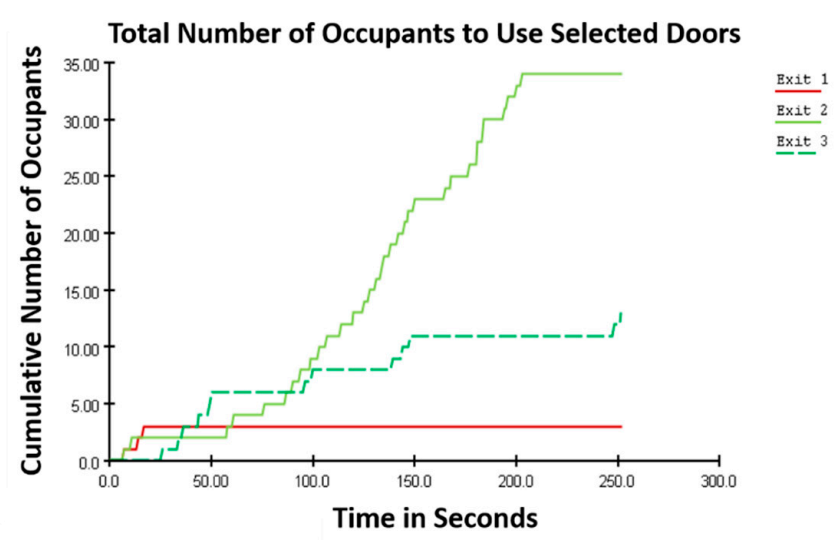

(b) Fire Incident

Figure 8. Impact of fire on occupants' exits (kitchen fire scenario).

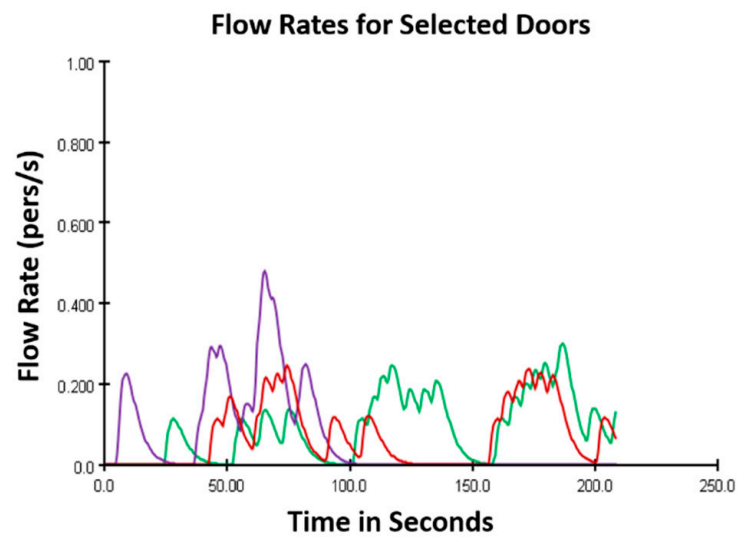

(a) Normal Situation

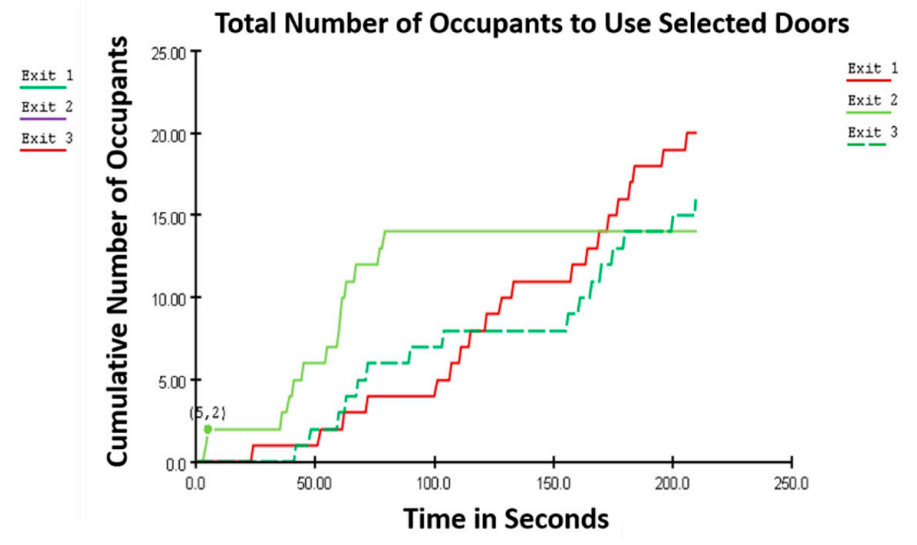

(b) Fire Incident

Figure 9. Impact of fire on the indoor occupants' flow rate (electrical fire scenario).

\subsection{Use of BIM for Evacuation Management}

The BIM model provides real-time visualization of sensor data through the visual programming code conducted in Dynamo. Sensors provide real-time data concerning temperature, humidity, and carbon dioxide. Figure 10a illustrates an example of the visualization of temperature data. In total, 20 sensors were installed in rooms with high occupancy to track the temperature variation. A color range was used to present the temperature levels: green (lowest temperature) to red (highest temperature). As shown in the legend, the temperature varies between $18.8^{\circ} \mathrm{C}$ and $21.8^{\circ} \mathrm{C}$. The highest temperatures are located in the Ph.D. students' offices, where the number of occupants is higher than in other rooms. For each room, the users can check the sensors' recorded data in the room properties (Figure 10b).

The results presented in the FDS and ABS are visualized and recorded in a BIM environment. The environmental data at several points will be exported to Dynamo, which will be responsible for generating interpolations to provide heat map values for each environmental parameter during the simulation interval. For example, the temperature values recorded during the fire simulations are exported and visualized in the BIM model. Figure 11 illustrates the temperature values, where the fire is located in the kitchen at $250 \mathrm{~s}$ of the simulation time. Based on the figure legend, the color range varies from blue, presenting the lowest temperature $\left(20^{\circ} \mathrm{C}\right)$, to red, presenting the highest temperature value $\left(420^{\circ} \mathrm{C}\right)$. The red zone shows the fire location while surrounding high temperatures precisely show the fire severity and spread. The temperature at the fire source reaches $420^{\circ} \mathrm{C}$; it impacts the surrounding areas with a temperature higher than $100^{\circ} \mathrm{C}$. In rooms 
far from the fire source, the temperature remains less than $60^{\circ} \mathrm{C}$. The electrical fire reaches lower temperature values compared to the kitchen scenario. The temperature at the fire's source reaches $120^{\circ} \mathrm{C}$.

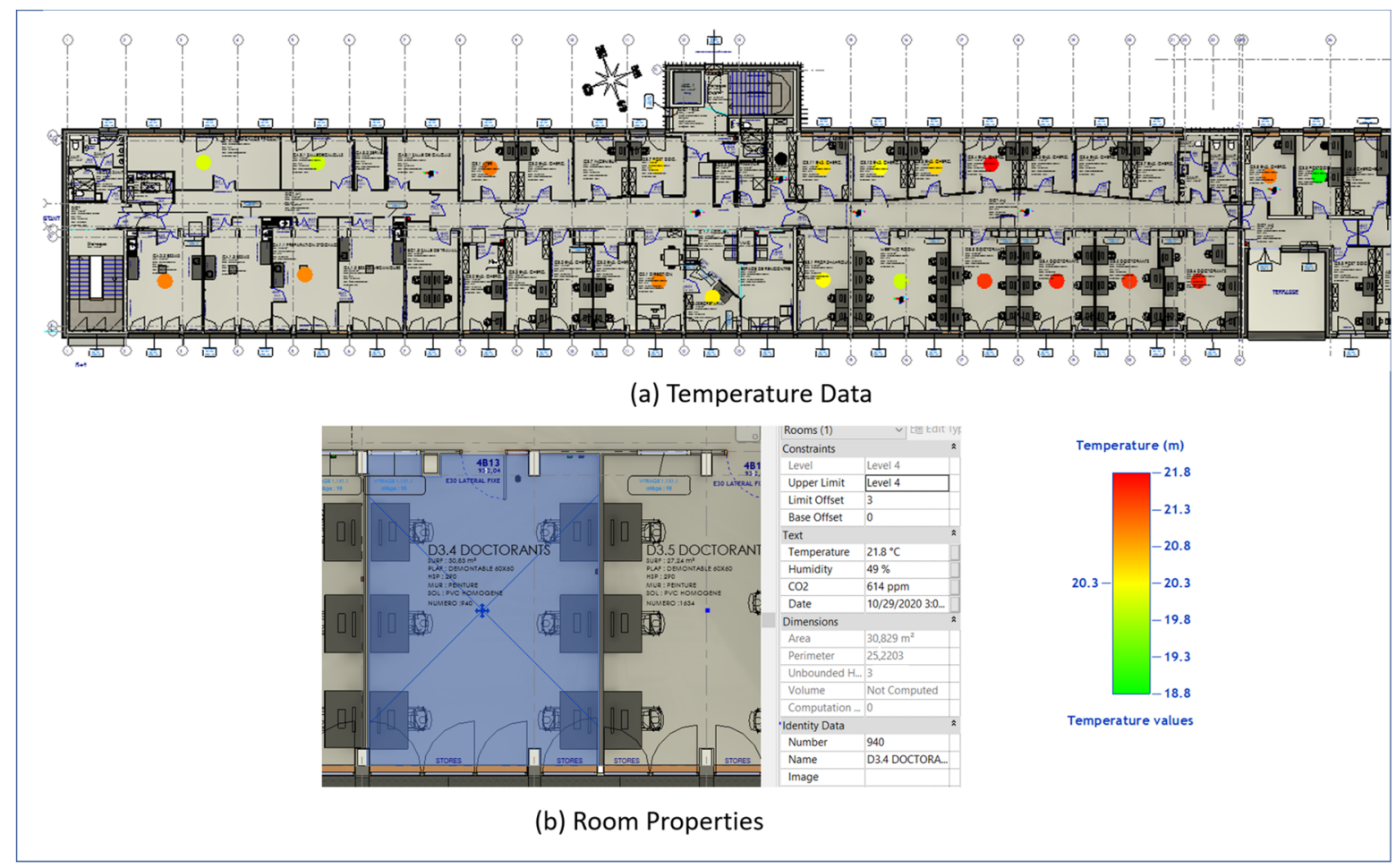

Figure 10. Illustration of the recorded temperature values in the BIM model.

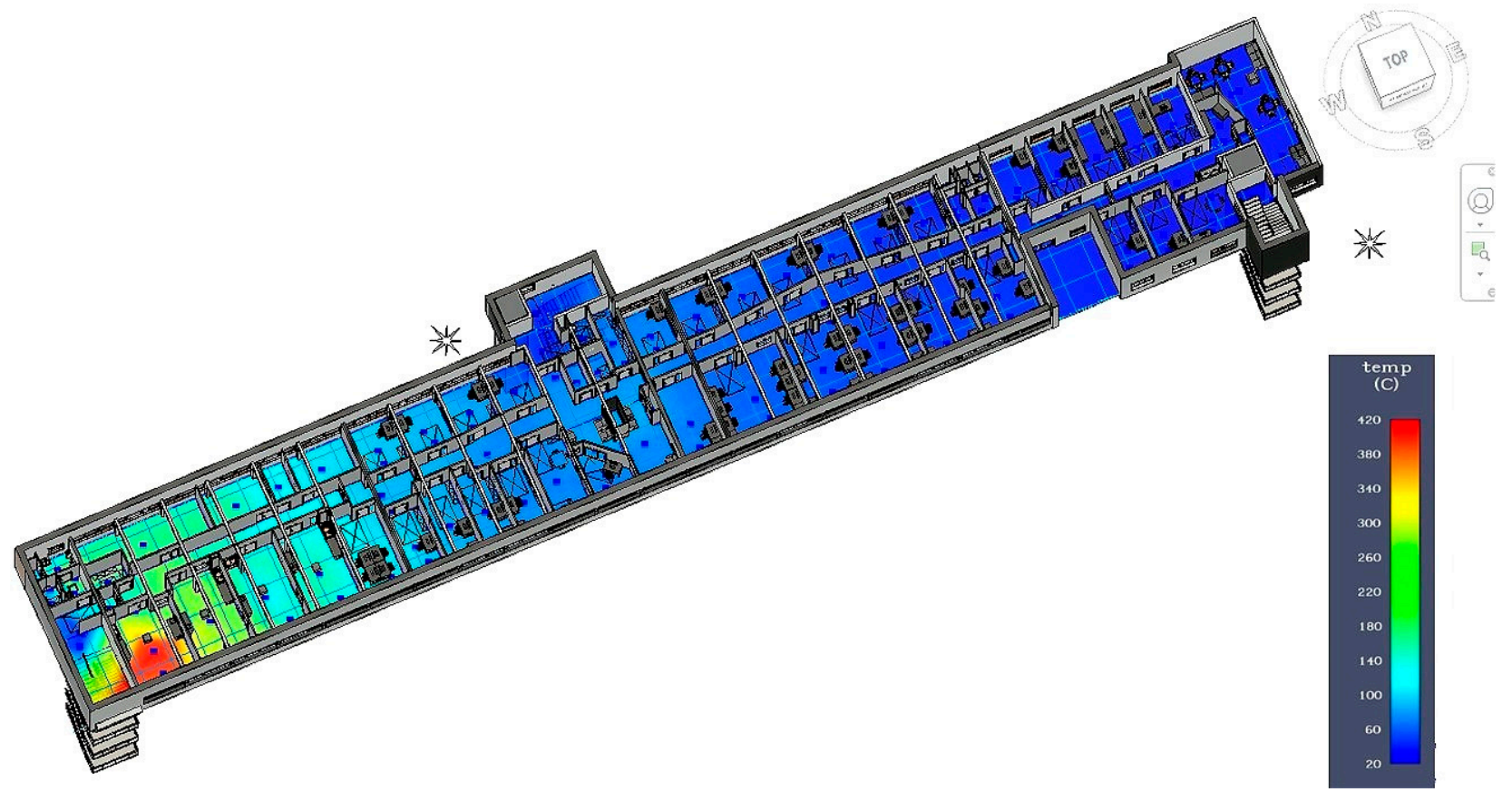

Figure 11. Temperature heat map (kitchen fire scenario).

The parameter values are illustrated in graph view. Figure 12 presents the $\mathrm{CO}$ variation for the kitchen during a fire. It shows that the $\mathrm{CO}$ emissions increase rapidly after the fire's ignition, and then remain constant. 


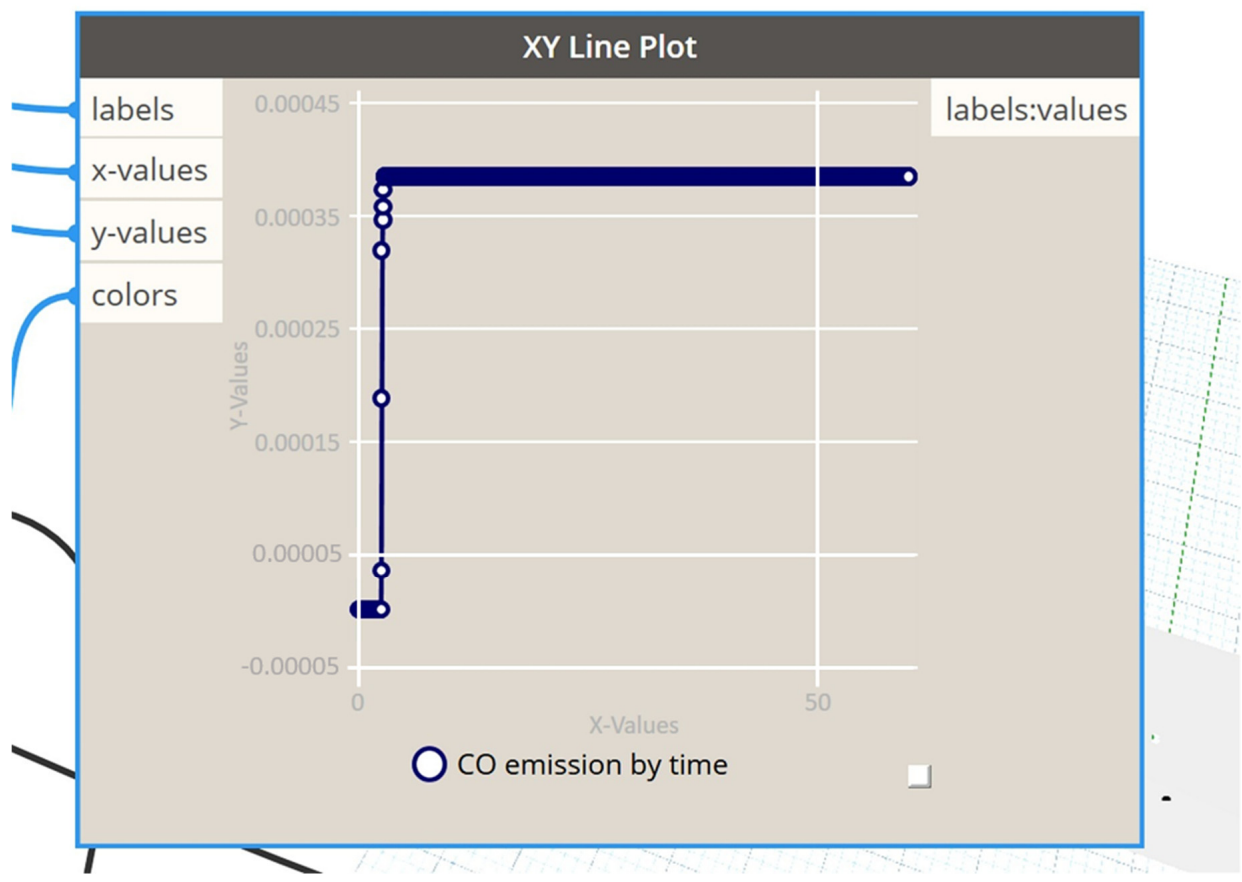

Figure 12. $\mathrm{CO}$ emissions by time in kitchen (kitchen fire scenario).

The fire and evacuation simulation outputs are visualized simultaneously in the BIM environment. The proposed system illustrates the optimal evacuation paths for occupants based on their locations and provides the necessary information such as the RSET, the distance needed, and the exit door. Figure 13 presents the evacuation paths for occupants from each room to the nearest exit in a normal situation. The legend color range gives the path length already achieved from each room to reach the closest exit during evacuation. It was noticed that during a normal situation, the longest evacuation path to the exit door is $34.4 \mathrm{~m}$. The BIM model will locate occupants' locations and change their directions according to the shortest and safest route during a fire event. Finally, the system displays occupants' information and sends them notification messages (Figure 14).

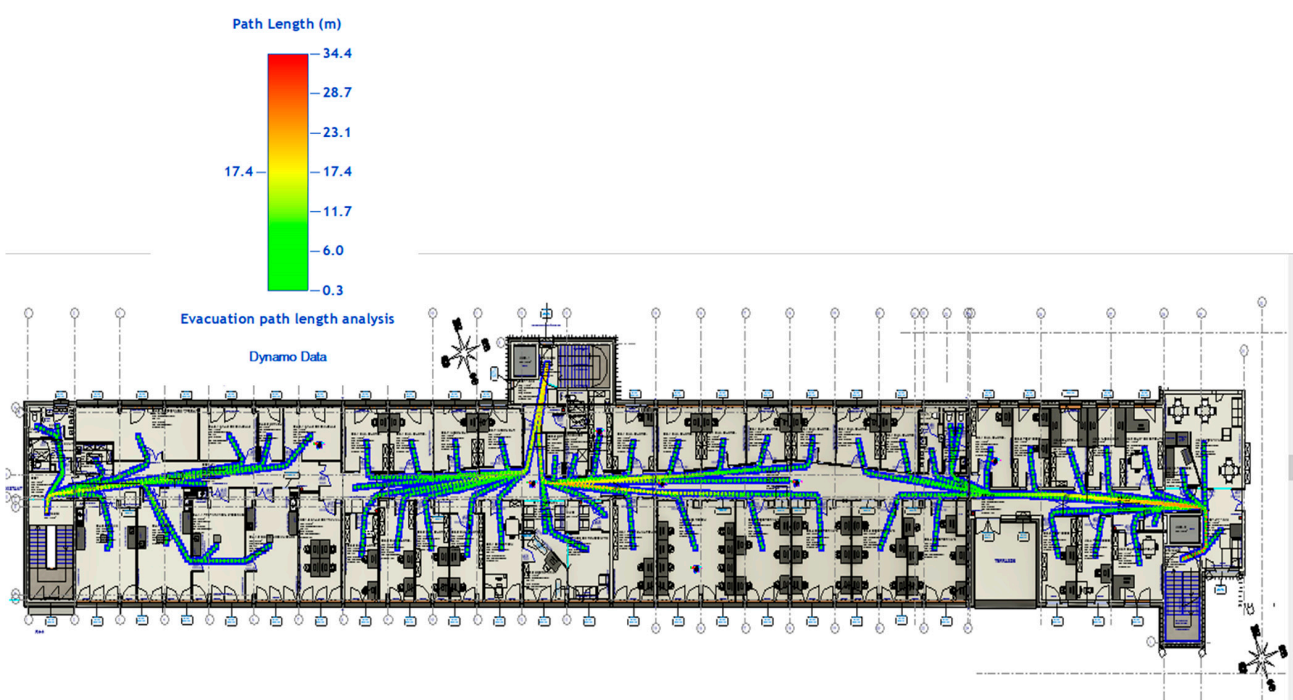

Figure 13. BIM visualization for evacuation paths. 


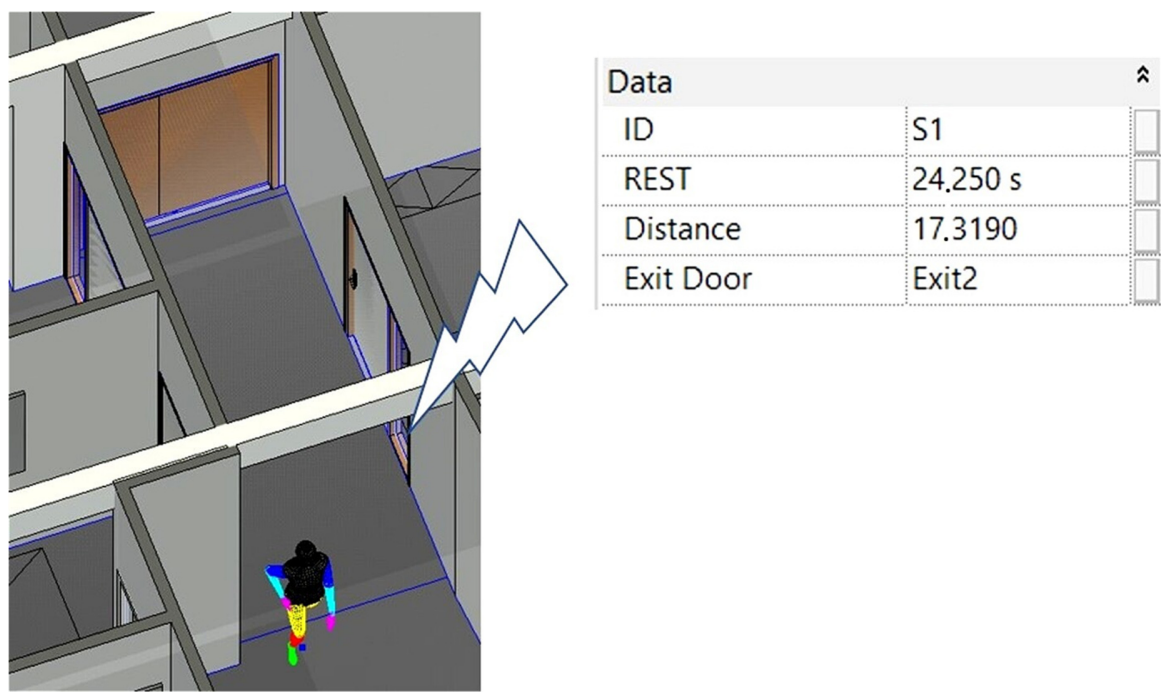

Figure 14. Occupants' information.

\section{Conclusions}

This study presented a comprehensive management system for fire evacuation that can (i) detect fire early; (ii) collect and analyze the environmental data provided by sensors; (iii) locate occupants; and (iv) provide users with the optimal evacuation paths. The system is based on the combination of several technologies and simulation tools. IoT and smart technology are used to detect a fire early and reduce false detection. FDS is used to simulate fire scenarios and ABS for crowd simulation and evacuation path generation. Both FDS and ABS provide a database used for the smart selection of evacuation paths in real time using AI. Moreover, this study highlighted the importance of BIM tools for (i) visualizing environmental data in a 3D model; (ii) tracking occupants in real time; and (iii) alerting occupants and providing them with the optimal evacuation paths.

The novelties of this study are:

- Using AI and previous simulations to learn and predict the best evacuation routes for occupants during a fire via the BIM environment.

- The system's power in visualizing fire and evacuation simulation outputs simultaneously in the BIM environment. It provides the evacuation route with accurate information regarding the distance needed to evacuate safely and the emergency exit to be taken.

- The capacity of occupants to interact with the system using a mobile application.

The system's capacity was illustrated through its application to a research building of Lille University. Two fire scenarios showed how the fire's location, type, and severity impact the occupants' selection of evacuation routes.

Future work will establish a dataset on the best evacuation paths during fire events in critical locations of the building. This dataset will be used with ML techniques for the real-time determination of the best evacuation paths in complex buildings.

Author Contributions: Conceptualization, R.W. and I.S.; Data curation, R.W.; Formal analysis, R.W.; Investigation, R.W.; Methodology, R.W. and I.S.; Project administration, I.S.; Software, R.W.; Supervision, I.S.; Validation, R.W. and I.S.; Visualization, R.W.; Writing-original draft, R.W.; Writing-review and editing, I.S. All authors have read and agreed to the published version of the manuscript.

Funding: This research received no external funding.

Data Availability Statement: Not Applicable, the study does not report any data.

Conflicts of Interest: The authors declare no conflict of interest. 


\section{References}

1. $\quad$ Brushlinsky, N.; Ahrens, M.; Sokolov, S.; Wagner, P. World Fire Statistics; CTIF: Ljubljana, Slovenia, 2017; pp. 1-56.

2. National Fire Data Center (U.S.). Topical Fire Report Series Civilian Fire Fatalities in Residential Buildings (2013-2015); U.S. Department of Homeland Security: Washington, DC, USA; FEMA: Washington, DC, USA; U.S. Fire Administration, National Fire Data Center: Emmitsburg, MD, USA, 2017; pp. 1-13.

3. Cheng, M.-Y.; Chiu, K.-C.; Hsieh, Y.-M.; Yang, I.-T.; Chou, J.-S. Development of BIM-Based Real-time Evacuation and Rescue System for Complex Buildings. In Proceedings of the 33rd International Symposium on Automation and Robotics in Construction (ISARC), Auburn, AL, USA, 18-21 July 2016.

4. Li, N.; Yang, Z.; Ghahramani, A.; Becerik-Gerber, B.; Soibelman, L. Situational awareness for supporting building fire emergency response: Information needs, information sources, and implementation requirements. Fire Saf. J. 2014, 63, 17-28. [CrossRef]

5. Lurz, F.; Mueller, S.; Lindner, S.; Linz, S. Smart Communication and Relative Localization System for Firefighters and Rescuers. In Proceedings of the 2017 IEEE MTT-S International Microwave Symposium (IMS), Honololu, HI, USA, 4-9 June 2017.

6. Onyenobi, T.; Hudson, J.; Ormerod, M. Impact of building geometry on fire spread rate. In Proceedings of the 22nd Annual ARCOM Conference, Birmingham, UK, 4-6 September 2006; pp. 739-748.

7. Darko, A.; Chan, A.P.C.; Yang, Y.; Tetteh, M.O. Computers in Industry Building information modeling (BIM)-based modular integrated construction risk management-Critical survey and future needs. Comput. Ind. 2020, 123, 103327. [CrossRef]

8. Zou, Y.; Kiviniemi, A.; Jones, S.W. A review of risk management through BIM and BIM-related technologies. Saf. Sci. 2017, 97, 88-98. [CrossRef]

9. Ding, L.Y.; Zhong, B.T.; Wu, S.; Luo, H.B. Construction risk knowledge management in BIM using ontology and semantic web technology. Saf. Sci. 2016, 87, 202-213. [CrossRef]

10. Tomek, A.; Matejka, P. The impact of BIM on risk management as an argument for its implementation in a construction company. Sci. Direct. 2014, 85, 501-509. [CrossRef]

11. Sloot, R.N.F.; Heutink, A.; Voordijk, J.T. Automation in Construction Assessing usefulness of 4D BIM tools in risk mitigation strategies. Autom. Constr. 2019, 106, 102881. [CrossRef]

12. Cortés-pérez, J.P.; Cortés-pérez, A.; Prieto-muriel, P. Automation in Construction BIM-integrated management of occupational hazards in building construction and maintenance. Autom. Constr. 2020, 113, 103115. [CrossRef]

13. Tang, Y.; Xia, N.; Lu, Y.; Varga, L.; Li, Q.; Chen, G.; Luo, J. BIM-based safety design for emergency evacuation of metro stations Autom. Constr. 2021, 123, 103511. [CrossRef]

14. Ma, G.; Wu, Z. BIM-based building fire emergency management: Combining building users' behavior decisions. Autom. Constr. 2020, 109, 102975. [CrossRef]

15. Li, N.; Becerik-Gerber, B.; Krishnamachari, B.; Soibelman, L. A BIM centered indoor localization algorithm to support building fire emergency response operations. Autom. Constr. 2014, 42, 78-89. [CrossRef]

16. Rashid, K.M.; Louis, J.; Fiawoyife, K.K. Automation in Construction Wireless electric appliance control for smart buildings using indoor location tracking and BIM-based virtual environments. Autom. Constr. 2019, 101, 48-58. [CrossRef]

17. Mirahadi, F.; McCabe, B.; Shahi, A. IFC-centric performance-based evaluation of building evacuations using fire dynamics simulation and agent-based modeling. Autom. Constr. 2019, 101,1-16. [CrossRef]

18. Fu, M.; Liu, R. BIM-based automated determination of exit sign direction for intelligent building sign systems. Autom. Constr. 2020, 120, 103353. [CrossRef]

19. Chen, A.Y.; Chu, J.C. TDVRP and BIM Integrated Approach for In-Building Emergency Rescue Routing. J. Comput. Civ. Eng. 2016, 30, C4015003. [CrossRef]

20. Cheng, M.Y.; Chiu, K.C.; Hsieh, Y.M.; Yang, I.T.; Chou, J.S.; Wu, Y.W. BIM integrated smart monitoring technique for building fire prevention and disaster relief. Autom. Constr. 2017, 84, 14-30. [CrossRef]

21. Shiau, Y.-C.; Tsai, Y.-Y.; Hsiao, J.-Y.; Chang, C.-T. Development of Building Fire Control and Management System in BIM Environment. Stud. Inform. Control 2013, 22, 15-24. [CrossRef]

22. Wang, B.; Li, H.; Rezgui, Y.; Bradley, A.; Ong, H.N. BIM based virtual environment for fire emergency evacuation. Sci. World J. 2014, 2014, 1-22. [CrossRef]

23. Mehra, S.; Tanmay. Disaster Detection System Using Arduino. In Proceedings of the 2017 International Conference on Information Communication and Embedded Systems (ICICES), Chennai, India, 23-24 February 2017; pp. 1-6. [CrossRef]

24. Singh, D.; Sharma, N.; Gupta, M.; Sharma, S. Development of System for Early Fire Detection using Arduino UNO. Int. J. Eng. Sci. Comput. 2017, 7, 10857-10860.

25. Khan, A.; Aesha, A.A.; Aka, J.S.; Rahman, S.M.F.; Rahman, M.J.U. An IoT Based Intelligent Fire Evacuation System. In Proceedings of the 2018 21st International Conference of Computer and Information Technology(ICCIT), Dhaka, Bangladesh, 21-23 December 2018; pp. 1-6.

26. Atila, U.; Ortakci, Y.; Ozacar, K.; Demiral, E.; Rakip Karas, I. SmartEscape: A mobile smart individual fire evacuation system based on 3D spatial model. ISPRS Int. J. Geo-Inf. 2018, 7, 223. [CrossRef]

27. Sowah, R.A.; Ofoli, A.R.; Krakani, S.N.; Fiawoo, S.Y. Hardware design and web-based communication modules of a real-time multisensor fire detection and notification system using fuzzy logic. IEEE Trans. Ind. Appl. 2017, 53, 559-566. [CrossRef]

28. Al Shereiqi, I.; Sohail, M. Smart Fire Alarm System Using IoT. J. Stud. Res. 2020, 1-9. [CrossRef] 
29. Wu, X.; Zhang, X.; Huang, X.; Xiao, F.; Usmani, A. A real-time forecast of tunnel fire based on numerical database and artificial intelligence. Build. Simul. 2021. [CrossRef]

30. Li, B.; Li, T.; Huang, D. Research on Automatic Fire Monitoring and Recognition Technology Based on Digital Image Processing Technology; Atlantis Press: Amsterdam, The Netherlands, 2019.

31. Jevtić, R.B. Fire simulation in house conditions. Tehnika 2016, 71, 160-166. [CrossRef]

32. Long, X.; Zhang, X.; Lou, B. Numerical simulation of dormitory building fire and personnel escape based on Pyrosim and Pathfinder. J. Chin. Inst. Eng. 2017, 40, 257-266. [CrossRef]

33. Xu, M.; Peng, D. PyroSim-Based Numerical Simulation of Fire Safety and Evacuation Behaviour of College Buildings. Int. J. Saf. Secur. Tour. 2020, 10, 293-299. [CrossRef]

34. Sun, Q. A BIM-based Simulation Framework for Fire Evacuation Planning. Master's Thesis, Oregon State University, Corvallis, OR, USA, June 2018.

35. Sun, Q.; Turkan, Y. A BIM-based simulation framework for fire safety management and investigation of the critical factors affecting human evacuation performance. Adv. Eng. Inform. 2020, 44, 101093. [CrossRef]

36. Sato, Y. Location-based Responsive Space for Multimedia Environment Using Ultra-wideband Technology. Master's Thesis, Concordia University, Montreal, QC, Canada, March 2011.

37. Rafiee, M.; Siddiqui, H.; Hammad, A. Improving Indoor Security Surveillance by Fusing Data from BIM, UWB and Video. In Proceedings of the the 30th ISARC, Montreal, QC, Canada, 11-15 August 2013; pp. 742-752.

38. Arthur, P.; Passini, R. Wayfinding: People, Signs, and Architecture, 1st ed.; McGraw-Hill: New York, NY, USA, $1992 ;$ pp. 1-238.

39. Gerges, M.; Demian, P.; Adamu, Z. Customising evacuation instructions for high-rise residential occupants to expedite fire egress: Results from agent-based simulation. Fire 2021, 4, 21. [CrossRef]

40. Piltaver, R.; Dovgan, E.; Gams, M. An Intelligent Indoor Surveillance System. CEPIC 2011, 7, 101-110.

41. Grytting, I.; Svalestuen, F.; Lohne, J.; Sommerseth, H.; Augdal, S.; Laedre, O. Use of LoD decision plan in BIM-projects. Sci. Direct. 2017, 196, 407-414. [CrossRef]

42. Klote, J.; Milke, J.; Tumbull, P.; Kashe, A.; Ferreira, M. Human Exposure to Smoke. In Handbook of Smoke Control Engineering; ASHRAE: Atlanta, GA, USA, 2012; pp. 177-188.

43. Yamada, T.; Akizuki, Y. Visibility and Human Behavior in Fire Smoke. In SFPE Handbook of Fire Protection Engineering, 5th ed.; Hurley, M.J., Gottuk, D.T., Hall, J.R., Jr., Harada, K., Kuligowsky, E.D., Puchovsky, M., Torero, J.L., Watts, J.M., Jr., Wieczorek, C.J., Eds.; Springer: New York, NY, USA, 2016; pp. 2181-2206.

44. Fridolf, K.; Andree, K.; Nilsson, D.; Frantzich, H. The impact of smoke on walking speed. Fire Mater. 2013, 38, 744-759. [CrossRef]

45. Zhong, M.; Shi, C.; Tu, X.; Fu, T.; He, L. Study of the human evacuation simulation of metro fire safety analysis in China. J. Loss Prev. Process Ind. 2008, 21, 287-298. [CrossRef]

46. Purser, D.; McAllister, J. Assessment of Hazards to Occupants from Smoke, Toxic Gases, and Heat. In SFPE Handbook of Fire Protection Engineering, 5th ed.; Springer: New York, NY, USA, 2016; pp. 2308-2428. [CrossRef]

47. Liu, R.; Jiang, D.; Shi, L. Agent-based simulation of alternative classroom evacuation scenarios. Front. Archit. Res. 2017, 5, 111-125. [CrossRef]

48. Thornton, C.; Konski, R.O.; Klein, B.; Hardeman, B.; Swenson, D. New Wayfinding Techniques in Pathfinder and Supporting Research. In Pedestrian and Evacuation Dynamics 2012; Springer: Berlin/Heidelberg, Germany, 2014. [CrossRef]

49. Peacock, R.D.; Hoskins, B.L.; Kuligowski, E.D. Overall and Local Movement Speeds During Fire Drill Evacuations in Buildings up to 31 Stories. Saf. Sci. 2011, 50, 1655-1664. [CrossRef]

50. NSAI. EN 1839:2017: Determination of the Explosion Limits and the Limiting Oxygen Concentration (LOC) for Flammable Gases and Vapours; CEN: Brussels, Belgium, 2017; pp. 1-48.

51. Khandoker, M.A.R.; Mou, R.J.; Muntaha, M.A.; Rahman, M.A. Numerical Simulation of Fire in a Multistoried Ready-Made Garments Factory Using PyroSim. AIP Conf. Proc. 2018, 1980, 050026. [CrossRef] 